\title{
Maintenance plus as needed budesonide plus formoterol was better than fixed dose for severe exacerbations in asthma
}

O'Byrne PM, Bisgaard H, Godard PP, et al. Budesonide/formoterol combination therapy as both maintenance and reliever medication in asthma. Am J Respir Crit Care Med 2005;171:129-36.

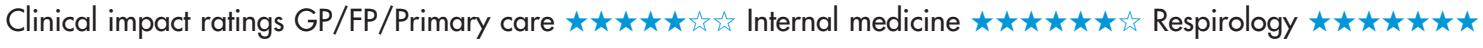

In patients with asthma, is budesonide (BUD) plus formoterol (FORM) (BUD+FORM) both for maintenance and symptom relief more effective than fixed dosing using BUD+FORM plus a short acting $\beta_{2}$ agonist (SABA) or a 4 fold higher dose of BUD plus SABA for reducing the rate of severe asthma exacerbations?

\section{METHODS}

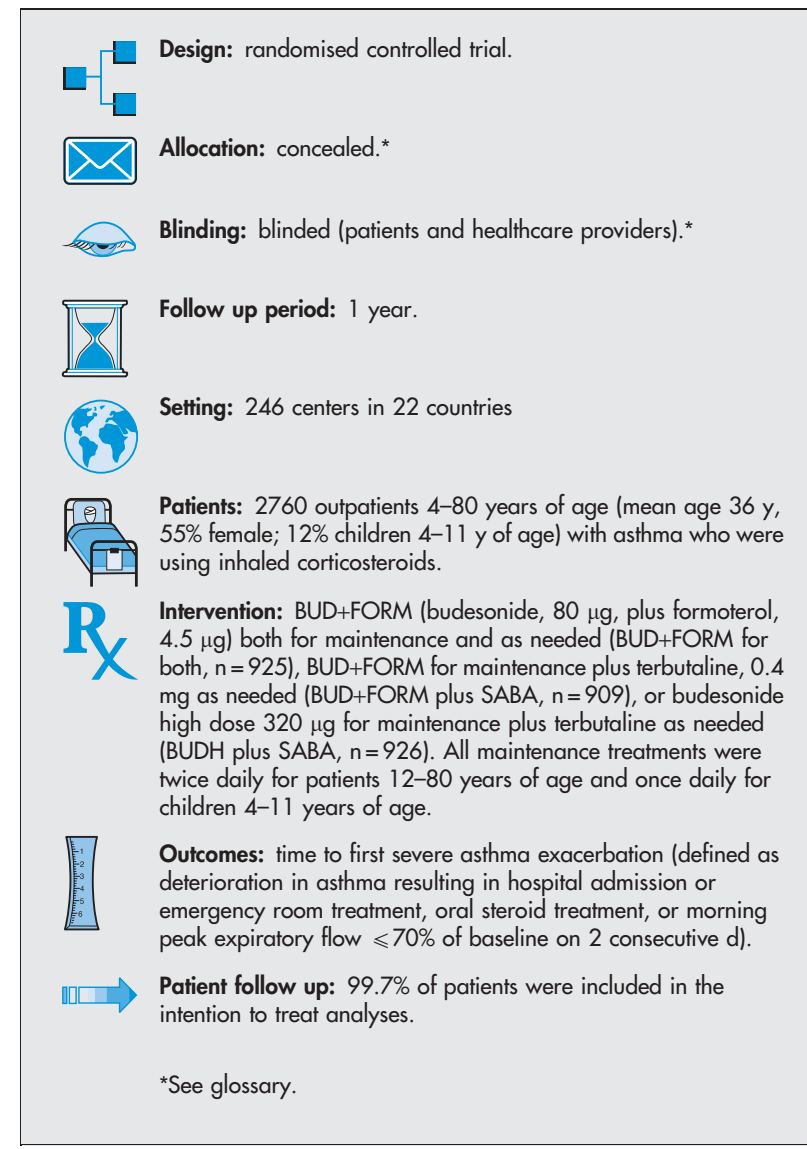

\section{MAIN RESULTS}

Time to first severe exacerbation was greater in the BUD+FORM for both group than in the BUD+FORM plus SABA group or BUD plus For correspondence: Dr P $\mathrm{P}$ M O’Byrne, St Joseph's Hospital, Hamilton, Ontario, Canada. obyrnep@mcmaster.ca

Source of funding: AstraZeneca R\&D, Lund, Sweden.
SABA group ( $\mathrm{p}$ values $<0.001$ ). Fewer patients in the BUD+FORM for both group than in the BUD+FORM plus SABA group or BUDH plus $\mathrm{SABA}$ group had $\geqslant 1$ severe asthma exacerbation (table).

\section{CONCLUSION}

In patients with asthma, budesonide plus formoterol (BUD+FORM) both for maintenance and symptom relief was more effective than fixed dosing using BUD+FORM plus a short acting $\beta_{2}$ agonist (SABA) or a 4 fold higher dose of budesonide plus SABA.

\section{A modified copy of this abstract appears in Evidence-Based Nursing.}

\section{Commentary}

M ost asthma can be controlled by inhaled long acting $\beta_{2}$ agonists (LABA) and corticosteroids (ICS), but this control is often inadequate in practice. 2 main combination products exist and have been associated recently with different approaches to control; the fluticasone/salmeterol combination with stepping up the dose to achieve full symptom control ${ }^{1}$ and the budesonide/formoterol (BUD+FORM) combination with varying the maintenance dose to control symptoms. ${ }^{2}$ The fast onset of bronchodilation and the dose response of formoterol prompted use of the BUD+FORM combination for regular dosing and relief in the study by O'Byrne et al. This approach provided better results, in prevention of exacerbations, than the combination or higher dose steroid alone with a SABA for relief, without adverse effects or excessive steroid doses. Benefits might be related to better adherence or intervention at the early stages of an exacerbation. Formoterol alone as relief medication has also shown benefits over a SABA. ${ }^{3}$

An important element is the corticosteroid dose chosen for the BUD+ FORM combination. Budesonide $80 \mu \mathrm{g}$ twice daily was used although adult patients had been on ICS 400-1000 $\mu$ g daily, (children 200-500 $\mu \mathrm{g})$. This would tend to allow exacerbations, bring out the differences between approaches, and reduce the number needed to treat but might not be the dose chosen in clinical practice.

The study by O'Byrne et al shows that a flexible approach with a single inhaler can be effective but it raises the question of whether alternative approaches of complete control at higher doses, or flexibility in response to symptoms, might be chosen to suit the needs and expectations of different patients.

$$
\begin{array}{r}
\text { P John Rees, MD } \\
\text { Guy's King's and St Thomas' School of Medicine, King's College } \\
\text { London, UK }
\end{array}
$$

1 Bateman ED, Boushey HA, Bousquet J, et al. Am J Respir Crit Care Med 2004; 170:836-44.

2 Ind PW, Haughney J, Price D, et al. Respir Med 2004;98:464-75.

3 Pauwels RA, Sears MR, Campbell M, ef al. Eur Respir J 2003;22:787-94.

Budesonide (BUD) plus formoterol (FORM) both for maintenance and symptom relief (BUD+FORM for both) $v$ fixed dosing using BUD+FORM or a 4 fold higher dose of BUD (BUDH), both with a short acting $\beta_{2}$ agonist (SABA) in asthma*

\begin{tabular}{llllr}
\hline Outcomes at 1 year & Comparison & Event rates & RRR (95\% CI) & NNT (CI) \\
\hline$\geqslant 1$ severe asthma & BUD+FORM for both $v$ BUD+FORM plus SABA & $16 \% v 27 \%$ & $41 \%$ (30 to 52) & 10 (8 to 13) \\
exacerbation & BUD+FORM for both $v$ BUDH plus SABA & $16 \% v 28 \%$ & $43 \%$ (31 to 53) & 9 (7 to 12) \\
\hline
\end{tabular}

*Abbreviations defined in glossary; RRR, NNT, and Cl calculated from Cox proportional hazard ratio in article. 